The lipids of dipping emulsions used to increase the drying rate of sultana grapes are absorbed and retained by the surface wax ${ }^{10}$. It is suggested that the addition of lipids (that is, fatty acids and their esters) with hydrophilic groups to the cuticular wax establishes a hydrophilic link between the hydrophobic surface of the grape and its watery contents, thus facilitating the flow of moisture through the cuticle.

I thank Dr. D. H. S. Horn, C.S.I.R.O. Division of Organic Chemistry, Melbourne, Victoria, for his advice. C.S.I.R.O.

F. RADLER

Horticultural Research Section, Merbein, Victoria, Australia.

${ }^{1}$ Sitte, P., and Rennier, R., Planta, 60, 19 (1963).

${ }^{2}$ Radler, F., and Horn, D. H. S., Austral. J. Chem., '7, 1059 (1965).

${ }^{3}$ Horrocks, R. L., Nature, 203, 547 (1964).

- Radler, F., J. Sci. Food Agric., 15, 864 (1964).

${ }^{5}$ Martin, R. J. L., and Stott, G. L., Austral. J. Agric. Res., 8, 444 (1957).

'Dudman, W. F., and Grncarevic, M., J. Sci. Food Agric., 13, 221 (1962).

Grncarevic, M., Amer. J. Enol. Viticult., 14, 230 (1964).

${ }^{8}$ Dudman, W. F., A ustral. J. Sci., 25, 168 (1962).

- Chambers, T. C., and Possingham, J. V., Austral. J. Biol. Sci., 16, 818 (1963).

${ }^{10}$ Radler, F., J. Sci. Food Agric. (in the press).

\section{Mechanical Stimulation of Feeding in Epiactis prolifera}

ThE feeding mechanisms of coelenterates were the subject of much interest at the turn of the century, and were investigated by such notable biologists as Loeb ${ }^{1}$, Jennings ${ }^{2}$ and Parker ${ }^{3}$. Renewed consideration has been given to these problems in the past few decades largely through the work of Pantin ${ }^{4}$, who used the sea anemone, Anemonia sulcata, and more recently through the experiments of Loomis ${ }^{5}$. The latter, who showed that small amounts of the tripeptide reduced glutathione activated feeding in the fresh-water Hydra littoralis, directed attention toward the chemical activation of feeding ${ }^{6,7}$. But the question of mechanical stimulation of feeding, although demonstrated in some sea anemones by earlier worker's ${ }^{2,8}$, has been neglected in recent years. In this communication, I describe some observations which show that the feeding response of the sea anemone Epiactis prolifera can be repeatedly activated by remarkably slight mechanical stimulation with inert objects.

Specimens of Epiactis prolifera of approximately $1 \cdot 2$ $2.5 \mathrm{~cm}$ diameter and $0.75-1.5 \mathrm{~cm}$ in height were collected from eelgrass beds in Friday Harbor, Washington. The animals were kept unfed in glass bowls on a sea-table of running fresh sea-water at about $13^{\circ} \mathrm{C}$.

When a small piece of Whatman No. 1 filter paper (about $0.5 \mathrm{~cm}$ square) was placed gently on the tentacles, those tentacles touching the paper contracted toward the mouth, and the adjacent tentacles both to the right and left bent toward the paper. When the paper was placed forcefully on the tentacles, the 'wave of stimulation' was greater, more tentacles contracting. Usually within 30-60 sec after the tentacles first touched the paper, the lips of the mouth moved toward the paper and ingested. it.

The tentacles are required for the reception of mechanical stimuli which activate feeding. The anemone did not seem to be aware of small pieces of paper placed on its oral disk only. If a nearby tentacle were made to touch the paper, however, within a few seconds adjacent tentacles started to envelop the paper and ingestion commenced.

This anemone can ingest a wide variety of inert and plant material. For example, a single specimen of Epiactis ingurgitated, in rapid succession during a 45-min span, Whatman filter paper, laboratory 'Kimwipes', paper towelling, pieces of eelgrass (Zostera) and the alga Fucus, small pebbles $(0 \cdot 2-0 \cdot 3 \mathrm{~g})$, and a piece of glass rod $(0 \cdot 2 \mathrm{~g})$.
All these objects were regurgitated later, covered with a layer of mucus. The regurgitation time for inert objects varied, some objects being retained for 2-10 h.

Animal food offered to Epiactis was usually swallowed within a minute. The anemones were fed flesh from local clams, shrimps, limpets, and sabellid worms. They would not ingest specimens of Epiactis half their size, but would ingest specimens of their own species about one-tenth their size. The latter were regurgitated several hours later, unharmed.

Following ingestion of animal tissue, the response to mechanical stimuli became gradually sluggish. For example, $8 \mathrm{~h}$ after feeding on the clam Protothaca sp., the anemones took from 10 to $30 \mathrm{~min}$ to ingest bits of paper, while the fasting control devoured the paper within 30 sec. One day after this feeding, the anemones did not respond to the paper at all and the tentacles seemed to be insensitive to mechanical stimulation. When a fresh piece of flesh was placed on Epiactis, however, it was trapped by the tentacles and feeding commenced immediately. After two days, unused food was usually regurgitated, and within one day after regurgitation the anemones were again responding avidly to inert objects.

The rapid triggering of feeding by mechanical stimulation which was so striking in Epiactis was not observed among other sea anemones from the Friday Harbor area that were tested, including Anthopleura elegantissima, Anthopleura xanthogrammica, Tealia sp., Metridium senile, Diadumine luceae, and the zoanthid Epizonthus scotinus.

This response of Epiactis prolifera is consistent and repeatable. Furthermore, the anemone is hardy and can be maintained in the laboratory with relative ease. Thus, it may afford a useful experimental system to study in coelenterates questions related to the nature, role and interaction of mechano- and chemo-receptors involved in co-ordinating a single response.

This work was supported by U.S. Public Health Service grant $G M 11226$.

Laboratory for Quantitative Biology,

HowARD M. LENHOFF*

University of Miami,

Coral Gables, Florida, and

Friday Harbor Laboratory,

University of Washington,

Friday Harbor, Washington.

* Investigator, Howard Hughes Medical Institute.

${ }^{1}$ Loeb, J., Pfluger, Arch. ges. Physiol., 9, 415 (1895).

2 Jennings, H. S., J. Exp. Zool., 2, 447 (1905).

${ }^{3}$ Parker, G. H., J. Exp. Zool, 22, 193 (1917).

${ }^{4}$ Pantin, C. F. A., and Pantin, A. M. P., J. Exp. Biol., 20, 6 (1943).

${ }^{5}$ Loomis, W. F., Ann. N.Y. Acad. Sci., 62, 209 (1955).

${ }^{6}$ Lenhoff, H. M., J. Gen. Physiol., 45, 331 (1961).

'Fulton, C. M., J. Gen. Physiol., 46, 823 (1963).

${ }^{8}$ Fleure, H. J., and Walton, C. L., Zool. Anz., 31, 212 (1906).

\section{Nitrogenous Excretion in Arachnids}

AnImals are known to excrete ammonia, urea, or uric acid as end-products of protein metabolism. So far as we can ascertain, the problem of nitrogenous excretion in arachnids needs more investigation. Since the work of Gorup-Besanez and $W^{1}{ }^{1}{ }^{1}$ in 1849 , guanine was regarded as taking the place of uric acid as the main nitrogenous end-metabolite in arachnids. The method of synthesis of guanine in these animals is unknown ${ }^{2}$.

Vajropala ${ }^{3}$ studied the excrements of the spider, Epeira diademata, by the specific enzymatic method of Schmidt ${ }^{4}$ and found that guanine accounts for up to 12 per cent of the dry weight of the excrements. Schmidt et al..$^{5}$ found that guanine accounts for more than 85 per cent of the total nitrogen of the excrements of two species of spiders, the silk spider, Nephila claviceps, and the garden spider, 